\title{
Importance of blast-design in reduction of blast-induced vibrations
}

\author{
AJAKA, Ebenezer Oyedele ${ }^{1}$, ADESIDA, Patrick Adeniyi ${ }^{2}$ \\ ${ }^{1}$ Department of Mining Engineering, the Federal University of Technology, Akure, Nigeria \\ ${ }^{2}$ Fountain Construction Company, Km 3, Akure-Owo Expressway, Akure, Nigeria
}

Email address:

akdenezer@gmail.com (Ajaka E. O.), adepatade@gmail.com (Adesida P. A.)

\section{To cite this article:}

AJAKA, Ebenezer Oyedele, ADESIDA, Patrick Adeniyi. Importance of Blast-Design in Reduction of Blast-Induced Vibrations. International Journal of Science, Technology and Society. Vol. 2, No. 3, 2014, pp. 53-58. doi: 10.11648/j.ijsts.20140203.14

\begin{abstract}
The dissipated energy generated during blasting creates environmental problems in the form of ground vibration, air overpressure and flyrock. With increasing mining and construction activities in areas close to human settlements, ground vibration has become a critical environmental issue as it can cause human annoyance and structural damage. The magnitude of ground movement was measured in term of Peak Particle Velocity (PPV) with the aid of USS 2000-DK Seismograph. Site constant $\mathrm{K}$, and site geological factor $m$ were determined for both quarries by plotting the log-log graph of the maximum PPV against scaled distance. The data collected for the twenty blasting activities in each of the quarry sites have shown that the peak particle velocities (PPV) recorded varied directly with the charge weight per delay but inversely with scaled distance (SD) and shot to monitored distance for both selected sedimentary and igneous rock. A comparative analysis between the results obtained for constant charge per delay of $1000 \mathrm{~kg}$, and monitoring distance of $500 \mathrm{~m}, 750 \mathrm{~m}$ and $1000 \mathrm{~m}$ were carried out. The magnitude of vibration for limestone is about twice that of granite at $300 \mathrm{~m}$ from the shot point and increase to about five times at $2200 \mathrm{~m}$. This is evident when considering the main mechanisms which contribute to ground motion dissipation such as; damping of ground vibrations which cause lower ground vibration frequencies with increasing distance, discontinuities causing reflection, refraction and diffraction, internal friction causing frequency dependent attenuation, which is greater for coarser grained rocks and geometrical spreading of rock.
\end{abstract}

Keywords: Blast-Induced Vibrations, Scaled Distance, Peak Particle Velocity, Seismograph, USBM Predictor Equation

\section{Introduction}

Blasting is the principal method of rock breakage in mining and construction projects throughout the world. This may probably be due to its distinct advantages like economy, efficiency, convenience and ability to break the hardest of rocks. However, only a portion of the total energy of the explosives used in blasting is consumed in breaking rocks while the rest is dissipated. The dissipated energy creates environmental problems in the form of ground vibration, air overpressure and flyrock. With increasing mining and construction activities in areas close to human settlements, ground vibration has become a critical environmental issue as it can cause human annoyance and structural damage [1].

During blasting, explosive charges produce a great amount of energy, some of which is transmitted in the form of stress waves beyond the area of the fragmented rock. The propagating stress waves travel in the rock and soil and produce ground vibrations that have the potential to cause damage to structures in the vicinity of the blast. Much of the damage that has occurred near blasting sites in the past has been to residential structures that have experienced cracks in walls and ceilings. However, there is the potential for more serious structural damage if the vibration levels are too high [2]. In the past forty years, many investigations have looked at the damage that ground vibrations from blasting may cause. The United States Bureau of Mines has done many of the studies, primarily concentrating on the damage to residential structures. Previous studies have found that peak particle velocity is the best index for predicting damage to residential buildings. On the basis of damage studies to residential type structures, the U.S. Bureau of Mines in 1962 recommended that the ground motion should not exceed a $50.0 \mathrm{~mm} / \mathrm{sec}$ peak particle velocity at a point of concern [3].

One of the most controversial issues facing the mining, quarrying and construction industries is ground vibration 
resulting from blasting. There are quite a number of court cases against these companies and citizens close to the proximities of their operations react negatively often to nuisance caused by blast induced vibration [4]. Recently there has been an increase in infrastructure and mineral resources developments. As a result quarrying activities has also increased to supply the needed construction materials. Consequently, there is an increase in the effects of ground vibration on the environment [5].

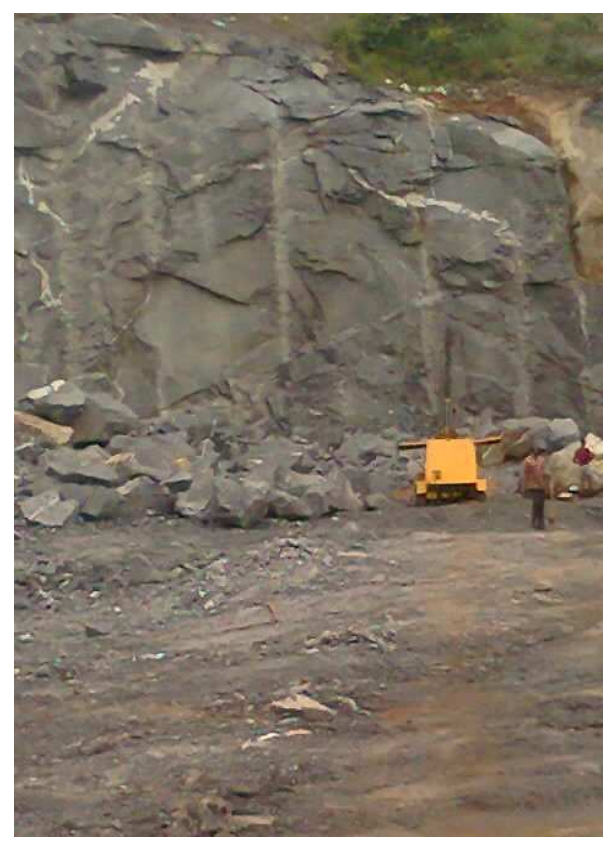

Figure 1. Octopus Quarry Face

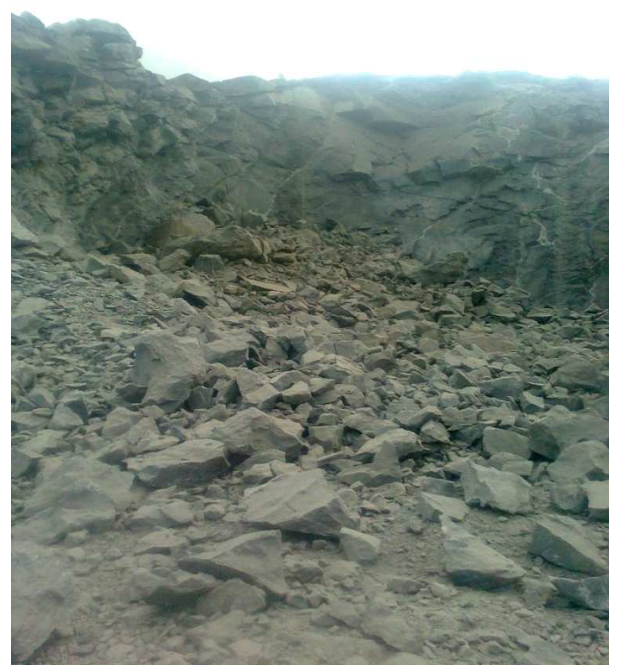

Figure 2. Geowork Limestone Quarry

\section{Materials and Method}

The materials used for the execution of this research included a seismograph for measuring blast-induced vibration, a Leica T47 total station for measuring distance, explosives (ANFO - ammonium nitrate and fuel oil,
Powergel B-1 SME), blasting accessories such as detonating cord, safety fuse and cap for blasting and a computer programme for analysing a regression model developed by $\mathrm{Pal}$ and Brahama [6]. This is in addition to several materials obtained from different literatures that were also used directly or indirectly in planning and execution of this research. Properties of Explosive Used are; Density = $1200 \mathrm{~kg} / \mathrm{m}^{3}$, Energy Libration $=3500 \mathrm{~kJ} / \mathrm{kg}$, Detonation Pressure $=13500 \mathrm{MPa}$, Velocity of Detonation $=5500 \mathrm{~m} / \mathrm{sec}$, Cartridge Lenght $=475 \mathrm{~mm}$, Cartridge Diameter $=50 \mathrm{~mm}$ and Cartridge Mass $=1.0 \mathrm{~kg}$.

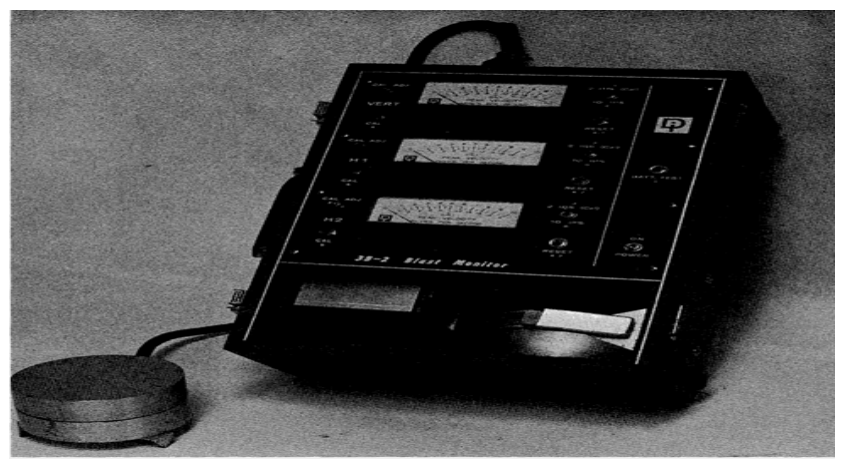

Figure 3. Seismograph

Using the Blast Seismograph shown in Figure 2, ground vibration components induced by blasting in two quarry sites were monitored to estimate site-specific attenuation factors for each of the quarries. The charge quantity per delay and the distance between the shot points in the quarries and the monitored stations were recorded carefully. The blasting models applied in these quarries were bench blasting. The blasting patterns and drilling patterns were observed and no changes were made in these patterns and the vibrations were measured on the ground surface with the aid of a blast monitor (seismograph).

The manual button was used to switch seismographs on and off to control the beginning and ending of the recording time to save their memory for recording useful blast data. The seismographs were switched on and off thirty minutes before and after blasting. The set-up of seismograph for measurement is such that it is toward the blast and its surface is kept as level as possible. Good coupling between seismograph and the ground is very important. The geophones where firmly attached to the ground by placing sandbags on them to avoid decoupling. The horizontal distance between each seismograph location and the blast were measured using a Leica T47 total station. Only necessary quantitative measurements and observations were performed for the shots on which vibration monitoring were based.

The safety patterns and protocols applied by the companies during the blasting have been followed in the derivation of the necessary data. In blasting operations at these sites, ANFO (blasting agent), gelatin dynamite (priming), and nonelectric detonators (firing) were used as explosives. In the 
prediction of ground vibration, although a lot of empirical relations have been established and used by different researchers in the past, the most reliable relations are those comprising the scaled distance and the particle velocity. The regression model by Pal and Brahama [6], developed from USBM predictor equation was used in this research. The scaled distance is a concept that utilizes the amount of explosive creating energy in seismic waves and the effect of distance. The scaled distance is derived by a combination of distance between blasting source and monitored points, and maximum charge per delay. The equation used for the scaled distance is given below:

$$
\mathrm{SD}=\frac{\mathrm{R}}{\sqrt{\mathrm{W}}}
$$

where: SD, scaled distance; $\mathrm{R}$, distance between the shot and the monitored station (m); and $W$, the maximum charge per delay $(\mathrm{kg})$. The USBM predictor equation was used for the estimation of the peak particle velocity (PPV):

$$
\mathrm{PPV}=\mathrm{K}(\mathrm{SD})^{\mathrm{m}}
$$

where; PPV, peak particle velocity; K, rock energy transfer coefficient; $m$, specific geological constant.

\subsection{Regression Model}

Pal and Brahma [6] did an analysis of blast vibration data for a suitable mathematical model to predict the future course of action for conducting controlled blasting operation in a mine keeping in view the variation of dependent variables and its effect on the stability of structures that is based on USBM predictor equation. The different parameters used in the formulation of the model are as follows:

Notations: $\mathrm{V}_{\mathrm{m}}=$ Peak particle velocity in $\mathrm{mm} / \mathrm{sec}$., $\mathrm{Q}=$ the maximum charge/delay in $\mathrm{kg}$. $\mathrm{D}=$ Distance of the monitoring point from the blast site in meters, $\mathrm{k}, \mathrm{m}=$ Constants dependent upon the rock types, type of explosives and blast design parameters. $\mathrm{D} / \sqrt{ } \mathrm{Q}=$ Square root scaled distance or simple scaled distance. The fundamental predictor equation of ground vibration is represented in the following form:

$$
\mathrm{Vm}=\mathrm{k}(\mathrm{D} / \sqrt{\mathrm{Q}})^{\mathrm{m}}
$$

Taking Log on both sides of the Equation (11), we get

$$
\log (\operatorname{Vm})=\log k+m \log (\mathrm{D} / \sqrt{\mathrm{Q}})
$$

This can be written in the form of a straight line as

$$
\mathrm{Y}=\mathrm{mx}+\mathrm{c}
$$

Where, $\mathrm{Y}=\log (\mathrm{Vm})$

$$
X=\log (D / \sqrt{Q})
$$

$$
C=\log k
$$

The $\mathrm{x}-\mathrm{y}$ relationship in Equation (5) is obviously a straight line with the slope ' $\mathrm{m}$ ' and the $\mathrm{Y}$ intercept ' $\mathrm{c}$ ' in order to plot the line, the values of $\mathrm{x}$ and $\mathrm{Y}$ are calculated using the values of $\mathrm{Vm}, \mathrm{D}$ and $\mathrm{Q}$. The intensity of blast vibration attenuates with distance and also depends on the maximum charge per delay. Peak particle velocity has been taken as the criterion of blasting damage. PPV is considered to be reliable predictor for ground vibrations caused by blasting. This predictor takes into the consideration that the total energy of ground motion generated around a blast varies directly with weight of explosives detonated and it is inversely proportional to the square of distance from the blasting point.

\section{Results}

Tables 1 and 2 show the blast-induced ground vibration measurements at Geowork limestone quarry and Octopus granite quarry respectively. Figures 4 and 5 show the chart of PPV against scaled distance for the selected sedimentary and igneous rocks respectively.

Figures 6 and 7 show the regression models analyses Graphs shown Log-Log of PPV against scaled distance in the selected sedimentary and igneous rocks respectively and Table 3 is the summary of site constants for selected rock types.

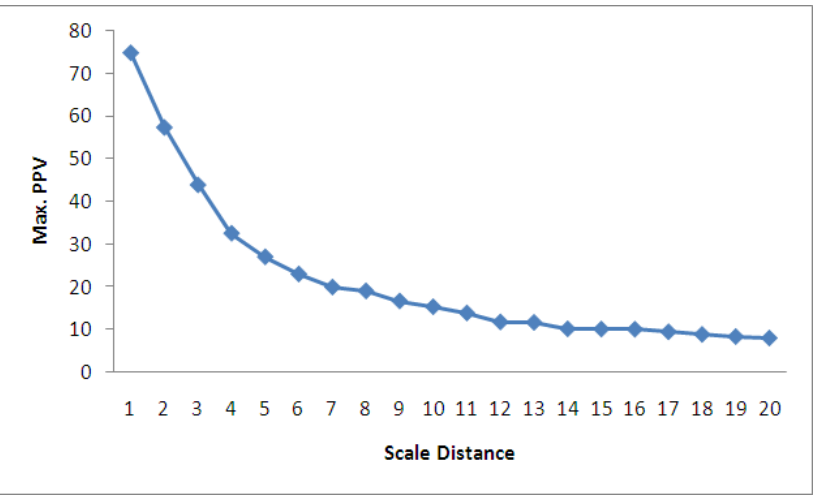

Figure 4. Chart of PPV against Scaled Distance in the Selected Sedimentary Rock

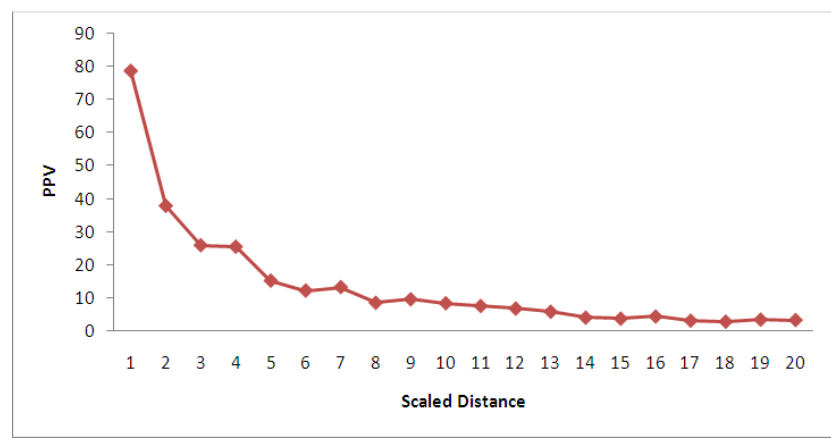

Figure 5. Chart of PPV against Scaled Distance in the Selected Igneous Rock. 
Table 1. Blast-induced Ground Vibration Measurements for Selected Sedimentary Rock

\begin{tabular}{|c|c|c|c|c|c|c|c|c|c|}
\hline \multirow{2}{*}{$\mathbf{S} / \mathbf{N}$} & \multirow{2}{*}{$\mathbf{D}(\mathbf{m})$} & \multirow{2}{*}{$\begin{array}{c}\mathbf{Q} \\
(\mathrm{Kg})\end{array}$} & \multicolumn{3}{|c|}{ Peak Particle Velocity $(\mathrm{mm} / \mathrm{s})$} & \multirow{2}{*}{$\begin{array}{c}\text { Max. PPV } \\
(\mathbf{m m} / \mathbf{s})\end{array}$} & \multirow{2}{*}{$\begin{array}{l}\text { Scaled Distance } \\
\quad(\mathbf{m} / \mathbf{K g})\end{array}$} & \multirow{2}{*}{$\begin{array}{c}\text { Log } \\
\text { Max.PPV }\end{array}$} & \multirow{2}{*}{$\begin{array}{c}\text { Log Scale } \\
\text { Distance }\end{array}$} \\
\hline & & & Vertical & Longitudinal & Transversal & & & & \\
\hline 1 & 300 & 350 & 74.60 & 74.55 & 74.05 & 74.60 & 16.04 & 1.87 & 1.21 \\
\hline 2 & 400 & 400 & 57.15 & 57.20 & 57.10 & 57.20 & 20.00 & 1.76 & 1.30 \\
\hline 3 & 500 & 400 & 43.75 & 43.80 & 43.65 & 43.80 & 25.00 & 1.64 & 1.40 \\
\hline 4 & 600 & 350 & 32.40 & 32.45 & 32.50 & 32.50 & 32.07 & 1.51 & 1.51 \\
\hline 5 & 700 & 350 & 27.00 & 26.95 & 26.45 & 27.00 & 37.42 & 1.43 & 1.57 \\
\hline 6 & 800 & 350 & 23.00 & 22.95 & 22.90 & 23.00 & 42.76 & 1.36 & 1.63 \\
\hline 7 & 900 & 350 & 19.95 & 19.90 & 19.85 & 19.95 & 48.11 & 1.30 & 1.68 \\
\hline 8 & 1000 & 400 & 18.85 & 19.05 & 18.95 & 19.05 & 50.00 & 1.28 & 1.70 \\
\hline 9 & 1100 & 350 & 16.70 & 16.65 & 16.45 & 16.70 & 58.80 & 1.22 & 1.77 \\
\hline 10 & 1200 & 400 & 15.30 & 15.30 & 15.35 & 15.35 & 60.00 & 1.19 & 1.78 \\
\hline 11 & 1300 & 400 & 13.85 & 13.90 & 13.75 & 13.90 & 65.00 & 1.14 & 1.81 \\
\hline 12 & 1400 & 350 & 11.70 & 11.75 & 11.80 & 11.80 & 74.83 & 1.07 & 1.87 \\
\hline 13 & 1500 & 400 & 11.65 & 11.70 & 11.60 & 11.70 & 75.00 & 1.07 & 1.88 \\
\hline 14 & 1600 & 350 & 10.15 & 10.10 & 10.20 & 10.20 & 85.52 & 1.01 & 1.93 \\
\hline 15 & 1700 & 400 & 10.00 & 10.05 & 10.15 & 10.15 & 85.00 & 1.01 & 1.93 \\
\hline 16 & 1800 & 450 & 10.05 & 10.10 & 9.85 & 10.10 & 84.85 & 1.00 & 1.93 \\
\hline 17 & 1900 & 450 & 9.45 & 9.40 & 9.50 & 9.50 & 89.57 & 0.98 & 1.95 \\
\hline 18 & 2000 & 450 & 8.65 & 8.90 & 8.85 & 8.90 & 94.28 & 0.95 & 1.97 \\
\hline 19 & 2100 & 450 & 8.35 & 8.30 & 8.40 & 8.40 & 99.00 & 0.92 & 2.00 \\
\hline 20 & 2200 & 450 & 8.05 & 7.90 & 7.95 & 8.05 & 103.71 & 0.91 & 2.02 \\
\hline
\end{tabular}

Table 2. Blast-induced Ground Vibration Measurements for the Selected Igneous Rock

\begin{tabular}{|c|c|c|c|c|c|c|c|c|c|}
\hline \multirow{2}{*}{$\mathbf{S} / \mathbf{N}$} & \multirow{2}{*}{$\mathbf{D}(\mathbf{m})$} & \multirow{2}{*}{$\mathbf{Q}(\mathrm{Kg})$} & \multicolumn{3}{|c|}{ Peak Particle Velocity $(\mathrm{mm} / \mathrm{s})$} & \multirow{2}{*}{$\begin{array}{c}\text { Max. PPV } \\
(\mathbf{m m} / \mathbf{s})\end{array}$} & \multirow{2}{*}{$\begin{array}{l}\text { Scaled Distance } \\
(\mathrm{m} / \mathrm{Kg})\end{array}$} & \multirow{2}{*}{$\begin{array}{c}\log \\
\text { Max.PPV }\end{array}$} & \multirow{2}{*}{$\begin{array}{c}\text { Log Scale } \\
\text { Distance }\end{array}$} \\
\hline & & & Vertical & Longitudinal & Transversal & & & & \\
\hline 1 & 300 & 1200 & 78.10 & 78.35 & 78.50 & 78.50 & 8.66 & 1.90 & 0.94 \\
\hline 2 & 400 & 850 & 36.85 & 36.90 & 37.75 & 37.75 & 13.72 & 1.58 & 1.14 \\
\hline 3 & 500 & 850 & 25.80 & 25.75 & 25.85 & 25.85 & 17.15 & 1.41 & 1.23 \\
\hline 4 & 600 & 1200 & 25.40 & 24.45 & 25.35 & 25.40 & 17.32 & 1.41 & 1.24 \\
\hline 5 & 700 & 850 & 15.15 & 15.05 & 15.10 & 15.15 & 24.01 & 1.18 & 1.38 \\
\hline 6 & 800 & 850 & 12.05 & 12.10 & 12.15 & 12.15 & 27.44 & 1.09 & 1.44 \\
\hline 7 & 900 & 1200 & 13.00 & 13.20 & 13.05 & 13.20 & 25.98 & 1.12 & 1.41 \\
\hline 8 & 1000 & 850 & 8.45 & 8.40 & 8.30 & 8.45 & 34.30 & 0.92 & 1.54 \\
\hline 9 & 1100 & 1200 & 9.35 & 9.45 & 9.50 & 9.50 & 31.75 & 0.98 & 1.50 \\
\hline 10 & 1200 & 1200 & 8.20 & 8.30 & 8.25 & 8.30 & 34.64 & 0.92 & 1.54 \\
\hline 11 & 1300 & 1250 & 7.50 & 7.45 & 7.50 & 7.50 & 36.77 & 0.88 & 1.57 \\
\hline 12 & 1400 & 1250 & 6.65 & 6.60 & 6.70 & 6.70 & 39.60 & 0.83 & 1.60 \\
\hline 13 & 1500 & 1200 & 5.75 & 5.70 & 5.70 & 5.75 & 43.30 & 0.76 & 1.64 \\
\hline 14 & 1600 & 850 & 3.95 & 3.90 & 3.25 & 3.95 & 54.88 & 0.60 & 1.74 \\
\hline 15 & 1700 & 850 & 3.55 & 3.60 & 3.65 & 3.65 & 58.31 & 0.56 & 1.77 \\
\hline 16 & 1800 & 1200 & 4.25 & 4.30 & 4.15 & 4.30 & 51.96 & 0.63 & 1.72 \\
\hline 17 & 1900 & 850 & 3.05 & 2.95 & 2.55 & 3.05 & 65.17 & 0.48 & 1.81 \\
\hline 18 & 2000 & 850 & 2.70 & 2.65 & 2.75 & 2.75 & 68.60 & 0.43 & 1.84 \\
\hline 19 & 2100 & 1200 & 3.35 & 3.30 & 3.15 & 3.35 & 60.62 & 0.53 & 1.78 \\
\hline 20 & 2200 & 1250 & 3.20 & 3.25 & 3.10 & 3.25 & 62.23 & 0.51 & 1.80 \\
\hline
\end{tabular}




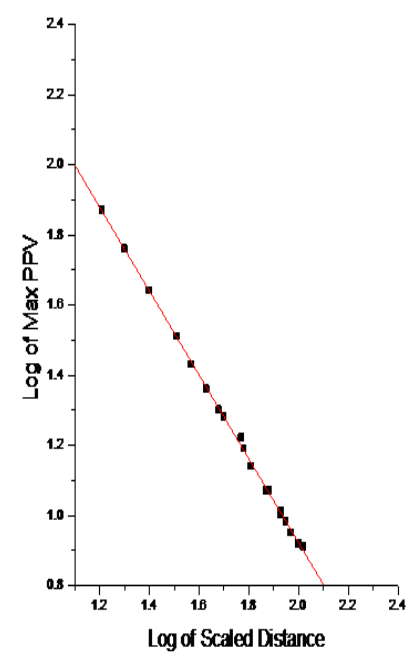

Figure 6. Regression Model Analysis Graph Shown Log-Log of PPV against Scaled Distance in the Selected Sedimentary Rock

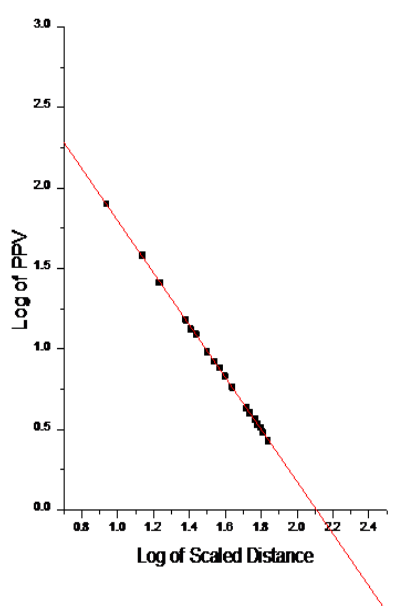

Figure 7. Regression Model Analysis graph Shown Log-Log of PPV against Scaled Distance in the selected Igneous Rock

Table 3. Summary of Site Constants for Selected Rock Types

\begin{tabular}{llll}
\hline Rock Type & Log K & K & M \\
\hline Sedimentary & 3.31394 & 2060.35 & -1.19572 \\
Igneous & 3.41754 & 2615.41 & -1.62034 \\
\hline
\end{tabular}

\section{Discussion}

The vibration intensities were monitored in terms of the Peak particle velocity in all the monitoring stations. The magnitude of vibrations recorded varied from a range of 3.10 to $78.5 \mathrm{~mm} / \mathrm{s}$ for the selected igneous rock and 2.65 to 74.60 for the selected sedimentary rock within a monitoring distance of 300 to $2200 \mathrm{~m}$ from the centre of the blast areas. These were dependent on the amount of explosive detonated per delay and the distance from the shot points to the monitoring stations. The data collected for the twenty blasting activities in each of the quarry sites have shown that the peak particle velocities (PPV) recorded varied directly with the charge weight per delay (Q) but varied inversely with scaled distance (SD) and shot to monitored distance (D) as shown in Figures 4 and 5. Figure 4 shows that ground particle velocity exceeded $50.0 \mathrm{~mm} / \mathrm{s}$ recommended by United State Bureau of Mines (USBM) from the shot point up to $400 \mathrm{~m}$. This indicates that any structure within the radius of $400 \mathrm{~m}$ from the blasting point can be damaged by blast induced vibration. But for our selected igneous rock, Figure 5 shows that structures within the radius of $320 \mathrm{~m}$ are exposed to danger of vibration. Both quarries have high PPV values at short distances, poopoowhich are gradually decreased with distances, due to the increasing effects of the geometric spreading and absorption. Though the charge weight per delay in Octopus quarry is more than twice of that in Geowork quarry, the PPV in Octopus is lesser than that of Geowork. This indicates that seismic attenuation is more in Octopus quarry due to damping and geometric spreading which are functions of site geological constant $\mathrm{m}$, in USBM predictor equation.

In the absence of the blast seismograph, a combination of scaled distances and site-specific constant factors, $\mathrm{K}$ and $m$ obtained from the regression lines in Figures 6 and 7 using software named ORIGIN, put together in Table 3 were used to predict the peak particle velocities associated with the vibration intensities of the quarry sites. The predicted PPV for the selected rocks using a constant distance of $500 \mathrm{~m}$ revealed that under the same condition, vibration intensities in igneous and sedimentary rocks vary sharply. Higher values of peak particle velocities were recorded and predicted in our selected sedimentary rock. This signifies that apart from the shot to monitored distance and explosive detonated, the geological factors of the site also contribute to the vibration intensities accompanying the quarry blast. PPV varies directly with the amount of explosive used in blasting rocks at a constant distance. The explosive used and other controllable factors in blast geometry are incorporated into the rock energy transfer coefficient $(\mathrm{K})$ used in USBM predictor equation. Computing the USBM predictor equation, we calculated the scaled distances at which the USBM allowable PPV limit of $50 \mathrm{~mm} / \mathrm{s}(2 \mathrm{in} / \mathrm{sec})$ will be obtainable. For our selected limestone site, the scaled distance for blast induced damage limit is $22.4195 \mathrm{~m} / \mathrm{kg}$, while $11.4980 \mathrm{~m} / \mathrm{kg}$ is for our selected granite site. This indicates that to have a safe blasting without damage to structures in the quarries vicinity, the ratio of the distance of the structures to the centre of the blasting point, to the square root of the quantity of explosive used must not be lesser than the values given above for both quarry sites. Consequently, charge per delay of $500 \mathrm{~kg}$ and $1750 \mathrm{~kg}$ can be detonated without exceeding the safe vibration criterion for the selected limestone and granite site respectively. 


\section{Conclusion}

A very good quarry design is necessary to reduce the effects of blast induced vibrations. From the above we can see how blast design can reduce the negative effects of blast vibrations if we have the knowledge of site specific constant factors which can be obtained using regression analysis. The above computation revealed that a maximum of $500 \mathrm{~kg}$ and $1750 \mathrm{~kg}$ charge weight per delay for limestone and granite respectively can be fired in a blast with respect to the safety of the structures, prevention of excessive flying rocks and draw-down of underground water in proximity if they are located outside the radius of $500 \mathrm{~m}$ from the centre of the blast site. Therefore, houses in the villages or sub-urban areas of distance $500 \mathrm{~m}$ or more will not suffer any vibration of greater intensity that could lead to any form of structural damage as the maximum PPV resulting from the above charge weight per delay for the selected limestone and granite are $50.16 \mathrm{~mm} / \mathrm{s}$ and $46.97 \mathrm{~mm} / \mathrm{s}$ respectively, which did not exceed the damage limit recommended by USBM.

A threshold peak particle velocity value of $50.16 \mathrm{~mm} / \mathrm{s}$ and $46.97 \mathrm{~mm} / \mathrm{s}$ and their corresponding charge weight of $500 \mathrm{~kg}$ and $1750 \mathrm{~kg}$ can be considered for a safe blast design in our selected sedimentary and igneous rock respectively if the nearest building to the quarry sites is at a distance of $500 \mathrm{~m}$.

\section{Recommendation}

It is highly recommended that in preparation for blasting, a good blast design must be done with respect to the site specific constants that act as the level of natural restriction of rock in-situ. With this, damage done to structures in close proximity of quarries, prevention of excessive flying rocks and draw-down of underground water by induced vibrations can be avoided if blast designs are well done.

\section{References}

[1] Abdel-Rasoul, E. I., (2000). Assessment of the particle velocity characteristics of blasting vibrations at Bani Khalid quarries. Bulletin of the Faculty of Eng., Vol. 28, No. 2, Assiut University, Assiut, Egypt, pp. 135 - 150.

[2] Douglas, E.L., (1989). An Investigation of Blasting Criteria for Structural and Ground Vibrations pp.1-1

[3] Dowding, C.H., (1985). Blast vibration monitoring and control. Englewoods Cliffs, NJ: Prentice-Hall; pp. 288-90.

[4] Dowding, C.H., (1992). Suggested Method for Blast Vibration Monitoring. Int J Rock Mech, January, 145-156.

[5] Federal Environmental Protection Agency, (1991). Interim Guidelines and Standard for Industrial Effluents, Gaseous Emission and Hazardous Waste in Nigeria. pp. 52

[6] Pal, B. K. and Brahma K.C., (2010). An Application of Regression Model for Evaluation of Blast Vibration in an Opencast Coal Mine - a Case Analysis, Canadian Journal on Computing in Mathematics, Natural Sciences, Engineering \& Medicine Vol. 1, No. 3, April 2010 pp106-109. 